\title{
Color Pure and Stable Blue Light Emitting Material Containing Anthracene and Fluorene for OLED
}

\author{
Hyuntae Park, Daehwan Oh, Jong-Won Park, ${ }^{\dagger}$ Jin-Hak Kim, ${ }^{\dagger}$ Sung-Chul Shin, Yun-Hi Kim, ${ }^{*}$ and Soon-Ki Kwon ${ }^{\dagger, *}$ \\ Department of Chemistry and RINS, Gyeongsang National University, Jinju 660-701, Korea \\ *E-mail: ykim@gnu.ac.kr \\ ${ }^{\dagger}$ School of Materials Science and Engineering and Engineering Research Institute (ERI), \\ Gyeongsang National University, Jinju 660-701, Korea.*E-mail: skwon@gnu.ac.kr \\ Received March 31, 2010, Accepted May 17, 2010
}

\begin{abstract}
A new blue light emitting anthracene derivative, 9,10-bis-(9',9'-diethyl-7'-t-butyl-fluoren-2'-yl)anthracene (BETF), has been designed and synthesized by a palladium catalyzed Suzuki cross-coupling. A theoretical calculation of the three-dimensional structure of BETF supports that it has a non coplanar structure and inhibited intermolecular interactions resulting in high luminescent efficiency and high color purity. BETF has good thermal stability with glass-transition temperature (Tg) of $131^{\circ} \mathrm{C}$. The PL maximum of BETF in solution and film were $438 \mathrm{~nm}$ and $440 \mathrm{~nm}$, respectively, showing pure blue emission. A multilayer device using BETF as emitting material exhibits maximum luminescence efficiency of $2.2 \mathrm{~cd} / \mathrm{A}$ and a pure blue emission (Commission Internationale de L'Eclairage (CIE) coordinates of $\mathrm{x}=0.15$, $\mathrm{y}=0.10)$
\end{abstract}

Key Words: Blue light emitting, Color pure, Anthracene

\section{Introduction}

Since the discovery of efficient organic light emitting diodes (OLED) based on low-molecular weight compounds and conjugated polymers, significant progress in materials and device science has led to the realization of full-color OLEDs with improved efficiencies and lifetimes. ${ }^{1-3}$ Now, the academic and industrial researches are progressing in display market. Especially, many new materials with RGB (red, green, blue) emission have been developed to meet the requirements of full color displays, because the development of high performance materials with desirable properties is very important. Compare to greenlight-emitting materials, many efforts are still needed to further improve the performance of blue-light-emitting materials. Because of their high energy levels, excellent blue-light-emitting materials can not only realize blue-light emission, but also facilitate white and other color emissions by adding another dopant emitter. It is thus important to develop high-performance bluelight-emitting materials with good stability and high fluorescence efficiency.

It is reported that anthracene derivatives have interesting photo- and electro-luminescent properties and good electrochemical properties. ${ }^{4-11}$ Moreover, various bulky substituents at 9, 10 positions of anthracene can be easily introduced. Fluorene also has a number of advantages, including its capability to emit in the blue part of the visible spectrum, chemical and photochemical stability, easy synthesis with high purity, liquid crystalline properties and durability under operation in a LED. ${ }^{12-16}$

Recently, we reported 9, 10-bis-(9',9'-diethyl-7'-diphenylamino-fluoren-2'-yl)anthracene (BDDFA) which are composed of antharcene and diphenylamino-fluorene group. The multilayer organic EL device constructed using 2\% BDDFA as dopant in host produces a bright blue emission with maximum efficiency of $4.17 \mathrm{~cd} / \mathrm{A}$ and exhibits a blue CIE (Commission
Internationale de l'Eclairage) chromaticity coordinates. $(\mathrm{x}=$ $0.14, \mathrm{y}=0.17)^{17}$

In the connection with recent report, we designed and synthesized new anthracene based blue emitting material which is composed of anthracene and $t$-butylated fluorene groups. The introduction of the bulky 9,9-diethyl-7-t-butyl-fluorenyl group in the 9,10-position of anthracene can suppress aggregation of planar anthracene segments which results in a pure and stable blue EL emission.

\section{Experiments}

Material synthesis. All reagent and solvents were purchased from Aldrich Chemical Co. and Fluka. Only analytical grade quality chemicals were used. Spectroscopic grade $\mathrm{CHCl}_{3}$ (Aldrich) was used for all absorption and emission experiments.

Instrument. ${ }^{1} \mathrm{H}-\mathrm{NMR}$ spectra were recorded using a Bruker AM-500 spectrometer, and chemical shifts are reported in ppm units with tetramethylsilane as internal standard. FT-IR spectra were obtained with a Bomem Michelson series FT-IR spectrometer. Melting points were determined using an Electrothermal Mode 1307 digital analyzer. Elemental analyses were performed by Leco Co. CHNS-932. Thermal analysis was carried out on a Dupont TGA 2100 thermogravimetric analyzer in a nitrogen atmosphere at a rate of $10{ }^{\circ} \mathrm{C} / \mathrm{min}$. Differential scanning calorimetery (DSC) was performed using a TA DSC 2010 device at a heating rate of $10{ }^{\circ} \mathrm{C} / \mathrm{min}$. UV-visible absorption spectra were obtained in chloroform on a Shimadzu UV-3100 spectrophotometer. The photoluminescence spectra were recorded on a Perkin-Elmer LS-50 fluorometer utilizing a lock-in amplifier system with a chopping frequency of $150 \mathrm{~Hz}$. Redox potentials of the compounds were determined by cyclic voltammetry (CV) using a BAS 100B electrochemical analyzer with a scanning rate at $100 \mathrm{mV} / \mathrm{s}$. The compound coated $\mathrm{Pt}$ disc was measured 
in a three electrode compartment cell with a Pt wire counter electrode and a $\mathrm{Ag} / \mathrm{AgNO}_{3}(0.1 \mathrm{M})$ reference electrode. The electrolyte was $0.1 \mathrm{M} \mathrm{Bu}_{4} \mathrm{NClO}_{4}$ solution in anhydrous acetonitrile, and the cell was purged with argon. Ferrocene was used for potential calibration (all reported potentials are referenced against $\mathrm{Ag} / \mathrm{Ag}^{+}$) and for reversibility criteria. Organic EL devices were fabricated using successive vacuum-deposition of $\mathrm{CuPc}, \alpha-\mathrm{NPD}, \mathbf{B E T F}, \mathrm{Alq}_{3}, \mathrm{LiF}$, and Al electrode on top of the ITO glass substrate. The ITO glass with a sheet resistance of about $10 \Omega$, supplied by Samsung Corning Co. was etched for the anode electrode pattern and cleaned in ultrasonic baths of isopropyl alcohol and acetone. The overlap area of $\mathrm{Al}$ and ITO electrodes is about $4 \mathrm{~mm}^{2}$. A UV zone cleaner (Jeilight Company) was used for further cleaning before vacuum deposition of the organic materials. Vacuum deposition of the organic materials was carried out under a pressure of $2 \times 10^{-7}$ torr. The deposition rate for organic materials was about $0.1 \mathrm{~nm} / \mathrm{s}$. The evaporation rate and the thickness of the film were measured with a quartz oscillator. OLED performance was studied by measuring the current-voltage-luminescence (I-V-L) characteristics, EL, and PL spectra at room temperature. I-V-L characteristics and CIE color coordinates were measured with a Keithley SMU238 and a BM-7 luminance-meter. EL spectra of the devices were measured utilizing a diode array rapid analyzer system (Professional Scientific Instrument Corp.) Fluorescence spectra of the solutions in chloroform were measured using a spectrofluorimeter (Shimadzu Corp.).

Synthesis of 9,10-dibromoanthracne.

The synthesis was caried out according to literature method: ${ }^{17}$ Yield: $90 \%$ mp $223-224{ }^{\circ} \mathrm{C}$. FT-IR $(\mathrm{KBr})\left(\mathrm{cm}^{-1}\right) 3031$, 1622, 1256, 1027, 927, 844, 746, 604, $577^{1} \mathrm{H}-\mathrm{NMR}$ (500 MHz, $\left.\mathrm{CDCl}_{3}\right) \delta 8.2(\mathrm{~s}, 4 \mathrm{H}), 7.5(\mathrm{~d}, 4 \mathrm{H})$.

Synthesis of 9,10-anthracene diboronic acid.

The synthesis was canied out according to literature method: ${ }^{17}$ Yield: $45 \%, \mathrm{mp} 214-216^{\circ} \mathrm{C}$. FT-IR $(\mathrm{KBr})\left(\mathrm{cm}^{-1}\right) 3497$, 3343, 3152, 1409, 1266. 1182, 1085, 1027, 755, $607{ }^{1} \mathrm{H}-\mathrm{NMR}$ $\left(500 \mathrm{MHz} \mathrm{CDCl}_{3}\right) \delta 8.0(\mathrm{~d}, 2 \mathrm{H}), 7.9(\mathrm{~d}, 2 \mathrm{H}), 7.45(\mathrm{~m}, 4 \mathrm{H}), 3.8$ (br., 4H).

\section{Synthesis of 2-bromo-9,9-diethyl fluorene.}

The synthesis was carried out according to literature method: ${ }^{17}$ Yield: $91 \%$, mp $52{ }^{\circ} \mathrm{C}$. FT-IR (KBr) $\left(\mathrm{cm}^{-1}\right) 3050,2950$, ${ }^{1} \mathrm{H}-\mathrm{NMR}\left(500 \mathrm{MHz}, \mathrm{CDCl}_{3}\right) \delta 7.8-7.6(\mathrm{~m}, 7 \mathrm{H}), 2.1(\mathrm{q}, 4 \mathrm{H}), 0.5$ $(\mathrm{t}, 6 \mathrm{H})$.

Synthesis of 2-bromo-7-t-butyl-9,9-diethyl fluorene. 2-Bromo-9,9-diethyl fluorene ( $5 \mathrm{~g}, 0.017 \mathrm{~mol}), 2,6$-di-t-butyl-4-meth$\mathrm{yl}$ phenol $(2.6 \mathrm{~g}, 0.012 \mathrm{~mol})$ and $50 \mathrm{~mL}$ of nitromethane were stirred. $\mathrm{AlCl}_{3}(2.3 \mathrm{~g}, 0.017 \mathrm{~mol})$ was slowly added to the mixture. After $8 \mathrm{~h}$, the reaction was terminated with ice-water. The crude product was purified by column chromatography using hexane as eluent. Yield: $5 \mathrm{~g}(82 \%), \mathrm{mp} 60{ }^{\circ} \mathrm{C}$. FT-IR (KBr) $\left(\mathrm{cm}^{-1}\right) 3050,2950,{ }^{1} \mathrm{H}-\mathrm{NMR}\left(500 \mathrm{MHz}, \mathrm{CDCl}_{3}\right) \delta 7.8-7.6(\mathrm{~m}$, $6 \mathrm{H}), 2.1$ (q, 4H), $1.4(\mathrm{~s}, 9 \mathrm{H}), 0.5(\mathrm{t}, 6 \mathrm{H})$.

Synthesis of 9,10-bis-(9',9'-diethyl-7'-t-butyl-fluoren-2'-yl) anthracene (BETF). 2-Bromo-7-t-butyl-9,9-diethyl fluorene $(1.4 \mathrm{~g}, 3.95 \mathrm{mmol})$, and 9,10-anthracene diboronic acid (0.5 g, $1.88 \mathrm{mmol})$ was dissolved in dried THF $(20 \mathrm{~mL})$. After $50 \mathrm{~mL}$ of $2 \mathrm{M}$ aqueous potassium carbonate was added through syringes to the mixture, the reaction mixture was degassed. Finally, 0.05 $\mathrm{g}$ of tetrakis(triphenylphosphine) palladium (0) was added to the mixture. The mixture was vigorously refluxed under nitrogen for $48 \mathrm{~h}$. When the mixture was cooled down to room temperature it was poured into $100 \mathrm{~mL}$ of mixture of methanol and deionized water (9:1). The crude product was purified by chromatography with dichloromethans:hexane $(1: 5)$ as eluent. Yield $=0.7 \mathrm{~g}$ (51\%). mp $310-312{ }^{\circ} \mathrm{C}$. FT-IR (KBr) $\left(\mathrm{cm}^{-1}\right) 3248,2958{ }^{1} \mathrm{H}$ NMR $\left(300 \mathrm{MHz}, \mathrm{CDCl}_{3}\right) \delta 8.13 \sim 7.78(\mathrm{~m}, 10 \mathrm{H}, \mathrm{Ar}-\mathrm{H}), 7.50 \sim$ 7.26 (m, 10H, Ar-H), 2 (q, 8H, - $\left.\mathrm{CH}_{2}-\right), 1.50$ (s, 18H, $t$-butyl), $0.59\left(\mathrm{t}, 12 \mathrm{H},-\mathrm{CH}_{3}\right)$.

\section{Results and Discussion}

Scheme 1 displays the synthetic route of 9,10-bis-(9',9'-diethyl-7'-t-butyl-fluoren-2'-yl)anthracene (BETF). BETF was synthesized by Suzuki coupling reaction of 9,10-anthracene diboronic acid and 2-bromo-7-t-butyl-9,9-diethyl fluorene, which is obtained by Friedel-Crafts acylation of 2-bromo-9,9-
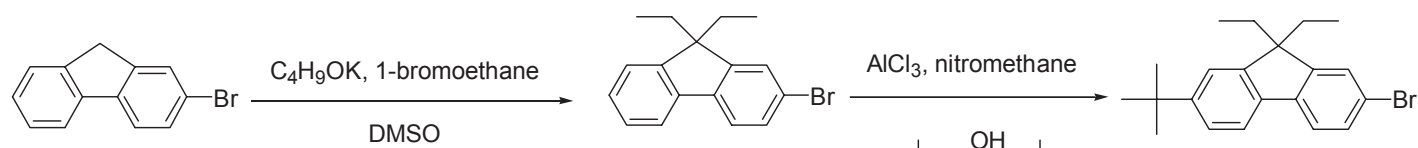<smiles>Cc1cc(C(C)(C)C)c(O)c(C(C)(C)C)c1</smiles>
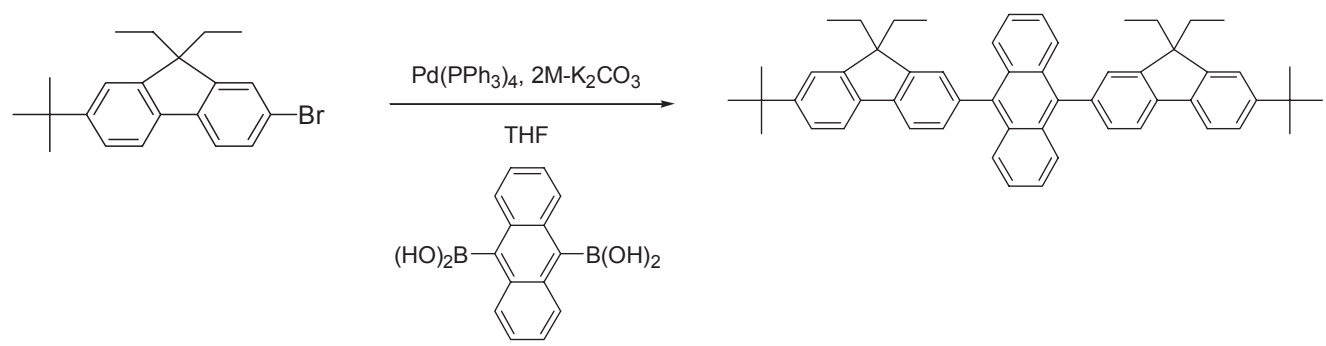

Scheme 1. Synthesis route of BETF 


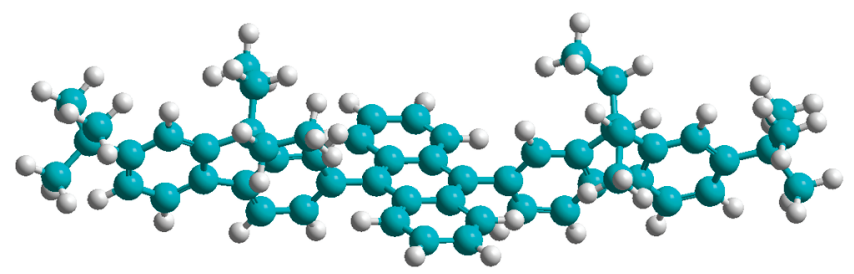

Figure 1. The stereostructure of BETF using the PM3 parameterization in the Hyper Chem 7.5 program (Hypercube).
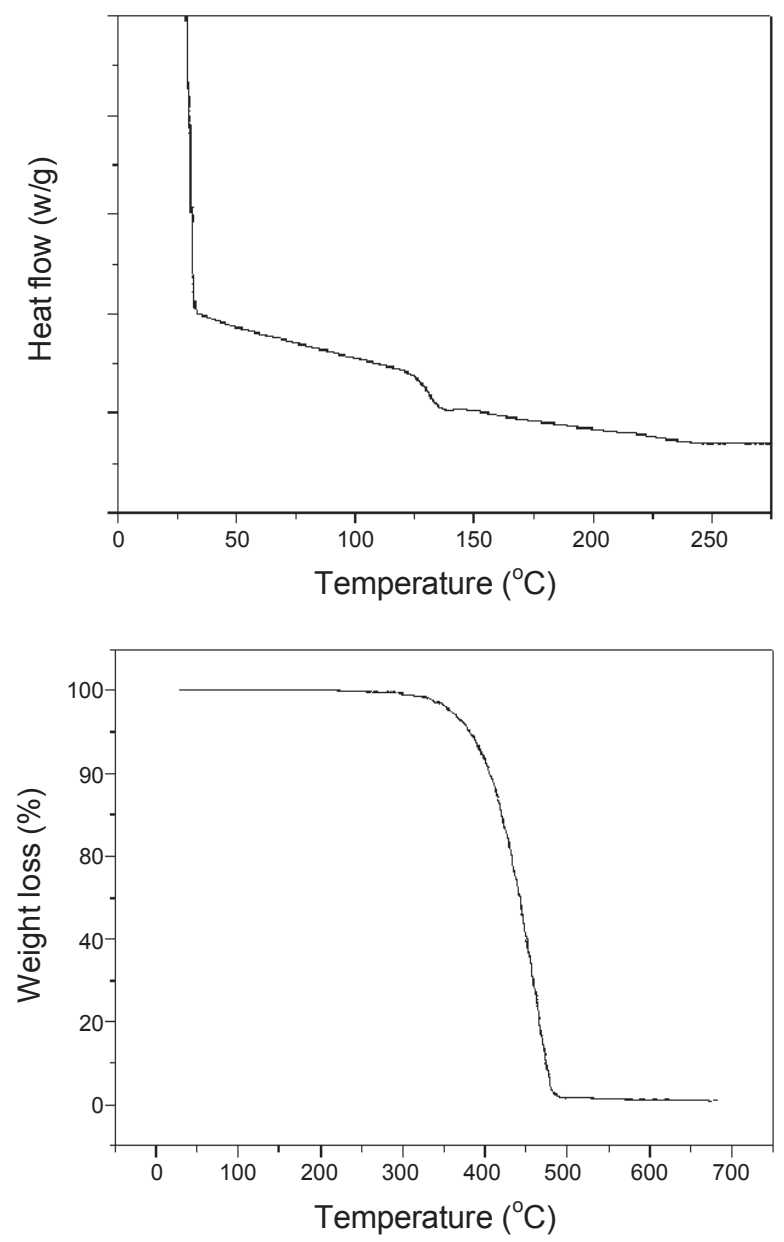

Figure 2. DSC and TGA curve of BETF.

diethyl fluorene. The spectroscopic results of FT-IR, ${ }^{1} \mathrm{H}-\mathrm{NMR}$, mass and the elemental analysis were found to be in good agreement with the proposed structure of the BETF. The obtained BETF was readily soluble in common solvents such as chloroform, methylene dichloride, and toluene.

Theoretical calculation using the PM3 parameterization in the Hyper Chem 7.5 program (Hypercube) was carried out for the characterization of the three-dimensional structure. The stereo structure of the BETF from the calculative analyses was shown in Figure 1. The $t$-butyl-fluorenyl in the 9 and 10 positions are significantly twisted toward the anthracene backbone into an angle of $102^{\circ}$ and $75^{\circ}$ for 9 and 10 positions, respectively. The three-dimensional structure from theoretical calculation

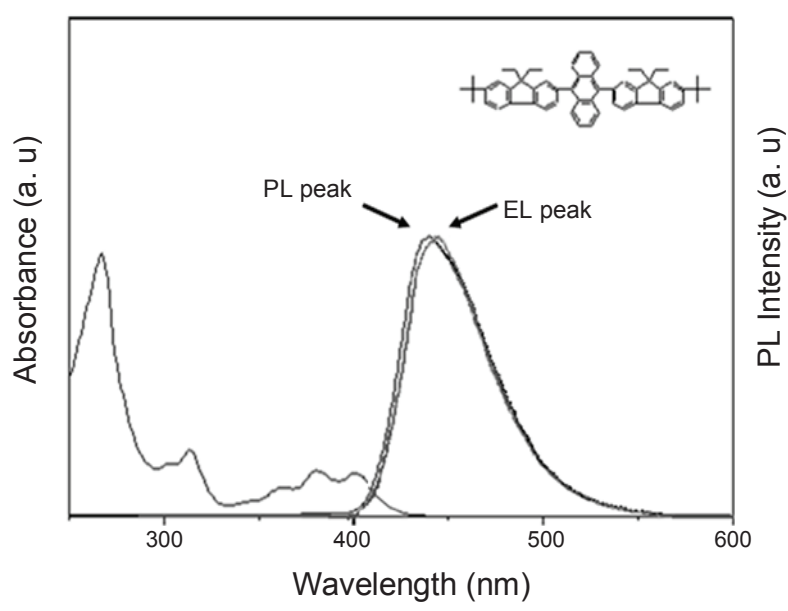

Figure 3. UV and PL spectra of BETF.

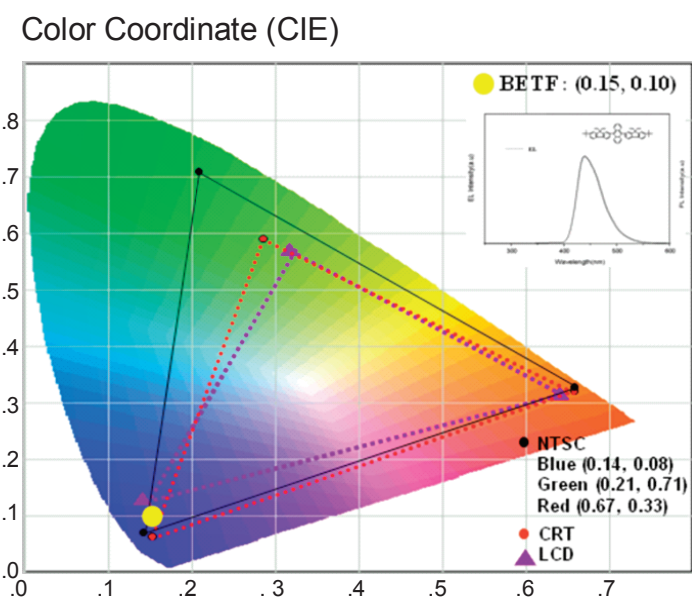

Figure 4. EL spectrum and the commission Internationale de L'Eclirage (CIE) coordinates of device for ITO/CuPc/ $\alpha-\mathrm{NPD} / \mathbf{B E T F} / \mathrm{Alq}_{3} / \mathrm{LiF} / \mathrm{Al}$

suggests that BETF has a non-coplanar structure with inhibited intermolecular interaction that results in high levels of luminescent efficiency and color purity.

The thermal properties of the BETF were evaluated by means of thermogravimetric analysis (TGA) and differential scanning calorimetry (DSC) in a nitrogen atmosphere. The $5 \%$ weight loss of the BETF begins at $358^{\circ} \mathrm{C}$, which means the material is stable enough to endure the temperature of the vacuum vapor deposition. The differential scanning calorimetry (DSC) measurement showed glass transition temperature at around $131{ }^{\circ} \mathrm{C}$ (Figure 2). The results show that the molecule has good thermal stability even though it is low molecular weight organic compound. It is supposed that introduction of bulky non-coplanar substituents into a rigid anthracene center allows the ability to form a thermally stable amorphous film. The thermally stable amorphous state is a basic requirement for materials used in LED, Generally, aggregation and microcrystallization have detrimental effects on the device stability.

Figure 3 showed the UV visible and PL spectra of dilute solution (in $\mathrm{CHCl}_{3}$ ). It showed absorption with $\lambda_{\max }$ at $315 \mathrm{~nm}$ due 


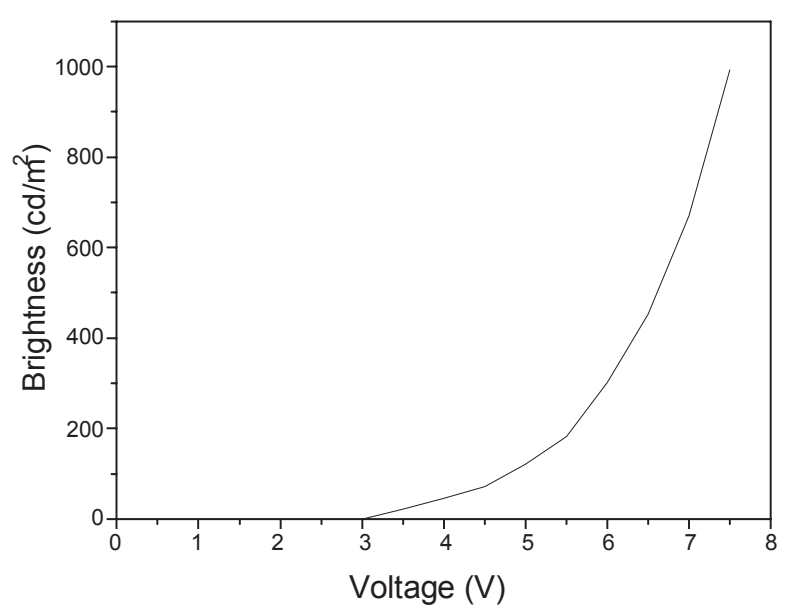

Figure 5. Voltage-brightness curve of ITO/CuPc/ $\alpha-\mathrm{NPD} / \mathrm{BETF} / \mathrm{Alq}_{3} /$ $\mathrm{LiF} / \mathrm{Al}$.

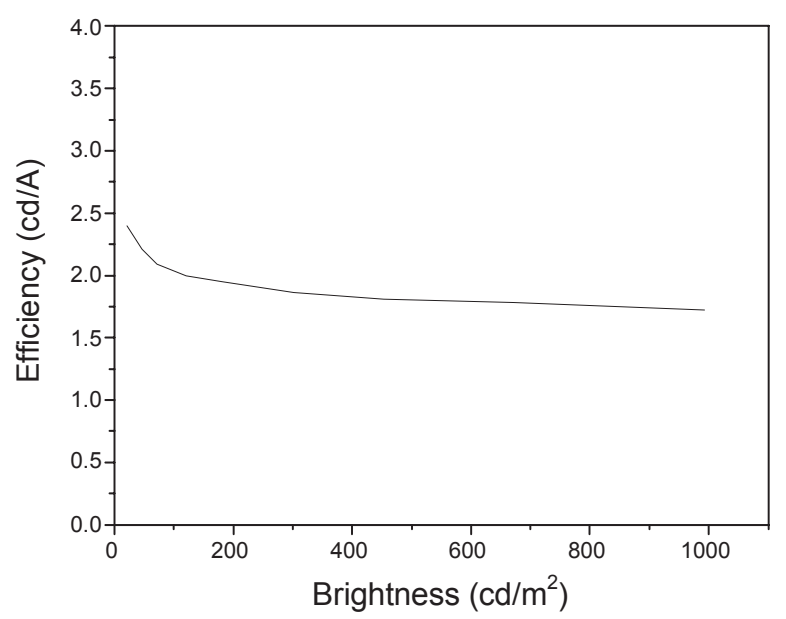

Figure 6. Brightness-efficiency curve of ITO/CuPc/ $\alpha-\mathrm{NPD} /$ BETF/ $\mathrm{Alq}_{3} / \mathrm{LiF} / \mathrm{Al}$.

to $\pi \rightarrow \pi^{*}$ transition of fluorene and $\lambda_{\max }$ at $350 \mathrm{~nm}, 370 \mathrm{~nm}$ and $395 \mathrm{~nm}$ due to characteristic transition of anthracene. Upon excitation at $315 \mathrm{~nm}$ and $395 \mathrm{~nm}$, the emission spectra showed same emission maximum at $438 \mathrm{~nm}$, which is the color pure blue emission. The PL quantum yield of the BETF was estimated to be $0.70 \pm 10 \%$ by using 9,10 -diphenylanthracene as the reference standard. The PL maximum of the BETF in the film was at $440 \mathrm{~nm}$. The small difference between the photoluminescence (PL) maximum of the sample showing pure blue emission in a solution and in a solid film suggest that there is minimal intermolecular interaction in the thin film state. The optical energy band gap of the BETF is $2.9 \mathrm{eV}$, which is calculated from the threshold of the optical absorption (425 nm).

The electrochemical behavior of BETF was investigated by cyclic voltammetry with a standard three electrodes electrochemical cell in a $0.1 \mathrm{M} \mathrm{Bu}_{4} \mathrm{NClO}_{4}$ solution in anhydrous acetonitrile at room temperature under nitrogen with a scanning rate of $200 \mathrm{mV} / \mathrm{s}$. A platinum working electrode and an $\mathrm{Ag} /$ $\mathrm{AgNO}_{3}(0.1 \mathrm{M})$ reference electrode were used. The oxidation onset potentials were measured to be $0.8 \mathrm{~V}$. The corresponding
HOMO energy level was calculated to to be $-5.6 \mathrm{eV}$. According to the UV edge of band gap energy $(2.9 \mathrm{eV})$ and HOMO (-5.6 $\mathrm{eV})$, the energy values of the lowest unoccupied molecular orbital (LUMO) was calculated to be $-2.7 \mathrm{eV}$.

To study the electroluminescent properties of BETF, multilayer device with the configuration of indium tin oxide (ITO)/ copper phthalocyanine (CuPc) $(20 \mathrm{~nm}) / 1,4$-bis[(1-naphthylphenyl)-amino]biphenyl ( $\alpha$-NPD) $(50 \mathrm{~nm}) / \operatorname{BETF}(20 \mathrm{~nm}) /$ tris (8-hydroxyquinoline) aluminum ( $\left.\mathrm{Alq}_{3}\right)(20 \mathrm{~nm}) / \mathrm{LiF}(1 \mathrm{~nm}) / \mathrm{Al}$ were fabricated, where ITO was used as anode, $\mathrm{CuPc}$ as the hole injection layer, $\alpha-\mathrm{NPD}$ as the hole transporting layer (HTL), $\mathrm{Alq}_{3}$ as the electron transporting layer (ETL), LiF as the electron injection layer, and $\mathrm{Al}$ as the cathode. The EL spectrum from non-doped device shows the maximum at $440 \mathrm{~nm}$. The high color purity $(\mathrm{x}=0.15, \mathrm{y}=0.10)$ in CIE for coordinates was observed at $977 \mathrm{~cd} / \mathrm{m}^{2}\left(58 \mathrm{~mA} / \mathrm{cm}^{2}\right)$ with turn on voltage of $3 \mathrm{~V}$. (Figure 4 and Figure 5). Long wavelength emission was not observed in the device, which could be attributed to the non-planar molecular structure of the material with bulky $t$-butyl groups. The results can be comparable with the reported 9, 10-bis(9',9'-diethyl-7'-diphenylamino-fluorene-2'-yl)anthracene (BDDFA). While the device using BDDFA with diphenylamino fluorene as dopant showed the blue CIE chromaticity coordinates $(\mathrm{x}=0.14, \mathrm{y}=0.17)$, device using BETF with $t$-butyl fluorene showed the blue CIE $(\mathrm{x}=0.15, \mathrm{y}=0.10)$ even non-doped device. Furthermore, it is noteworthy that the EL efficiency of the devices do not drop obviously when brightness increased, and when the brightness reaches its maximum, the devices have still maintain a efficiency of $2.2 \mathrm{~cd} / \mathrm{A}$, which indicates that the device still stable under extreme operating conditions (Figure 6).

\section{Conclusion}

The new blue light emitting anthracene derivative, 9,10-bis(9',9'-diethyl-7'-t-butyl-fluoren-2'-yl)anthracene (BETF), was designed and synthesized by alkylation, acylation, and Suzuki coupling reaction. The non-doped device with structure of the $\mathrm{ITO} / \mathrm{CuPc} / \alpha-\mathrm{NPD} / \mathrm{BETF} / \mathrm{Alq}_{3} / \mathrm{LiF} / \mathrm{Al}$ device show high color pure blue-light emission (Commission Internationale de L'Eclairage (CIE) coordinates of $\mathrm{x}=0.15, \mathrm{y}=0.10$ ) and stable efficiency of $2.2 \mathrm{~cd} / \mathrm{A}$.

Acknowledgments. This research was financially supported by MKE and KIAT through the Workforce Development Program in Strategic Technology, by Strategic Technology Under Ministry of Knowledge Economy of Korea and by Basic Science Research Program through the National Research Foundation of Korea (NRF) funded by the Ministry of Education, Science and Technology (2010-0015390).

\section{References}

1. Tang, C. W.; Vanslyke, S. A. Appl. Phys. Lett. 1987, 51, 913.

2. Burroughes, J. H.; Bradley, D. D. C.; Brown, A. R.; Mackay, R. N.; Friend, R. H.; Burns, P. L.; Holms, A. B. Nature 1990, 347, 539.

3. Noda, T.; Ogawa, H.; Noma, N.; Shirota, Y. J. Mater. Chem. 1999, $2,2177$.

4. Kim, Y. H.; Kwon, S. K.; Yoo, D. S.; Rubner, M. F.; Wrighton, M. S. Chem. Mater. 1997, 9, 2699. 
5. a) Kim, Y. H.; Jeong, H. C.; Kim, S. H.; Yang, K.; Kwon, S. K. Adv. Funct. Mater. 2005, 15, 1799. b) Shi, J.; Tang, C. W. Appl. Phys. Lett. 2002, 80, 3201. c) Liu, T. H.; Shen, W. J.; Balaganesan, B.; Yen, C. K.; Iou, C. Y.; Chen, H. H.; Chen, C. H. Synth. Met. 2003, 137, 1033. d) Kim, Y. H.; Shin, D. C.; Kim, S. H.; Ko, C. H.; Yu, H. S.; Chae, Y. S.; Kwon, S. K. Adv. Mater. 2001, 13, 1690. e) Kim, Y. H.; Lee, S. J.; Jung, S. Y.; Byeon, K. N.; Kim, J. S.; Shin, S. C.; Kwon, S. K. Bull. Korean Chem. Soc. 2007, 28, 443. f) So, K. H.; Park, H. T.; Shin, S. C.; Lee, S. K.; Lee, D. H.; Lee, K. H.; Oh, H. Y.; Kwon, S. K.; Kim, Y. H. Bull. Korean Chem. Soc. 2009, 30,1611 .

6. a) Benzman, R.; Faulkner, L. R. J. Am. Chem. Soc. 1972, 94, 6317. b) Berlan, I. B. Handbook of Fluorescence Spectra of Aromatic Molecules, 2nd ed.; Academic Press: New York, 1971.

7. Kim, Y. H.; Kwon, S. K. J. Appl. Polym. Sci. 2006, 100, 2151.

8. Garay, R. O.; Narmann, H.; Mullen, K. Macromolecules 1994, 27, 1922.
9. Shih, H. T.; Lin, C. H.; Shih, H. H.; Cheng, C. H. Adv. Mater. 2002, 14,1409

10. Danel, K.; Hwang, T. H.; Lin, J. T.; Tao, Y. T.; Chen, C. H. Chem. Mater. 2002, 14, 3860.

11. Yu, M. X.; Duan, J. P.; Lin, C. H.; Chung, C. H.; Tao, Y. T. Chem. Mater. 2002, 14, 3958.

12. Wei, Y.; Chen, C. T. J. Am. Chem. Soc. 2007, 129, 7478.

13. Rathnayake, H. P.; Cirpan, A.; Delen, Z.; Lahti, P. M.; Karasz, F. E. Adv. Funct. Mater. 2007, 17, 115.

14. Montes, V. A.; Perez, B. C.; Agarwal, N.; Shinar, J.; Anzenbacher, P. J. Am. Chem. Soc. 2006, 128, 12436.

15. Culligan, S. W.; Chen, A. C-A.; Wallace, J. U.; Klubek, K. P.; Tang, C. W.; Chen, S. H. Adv. Funct. Mater. 2006, 16, 1481.

16. Tang, C.; Liu, F.; Xia, Y. J.; Lin, J.; Xie, L. H.; Zhong, G. Y.; Fan, Q. L.; Huang, W. Org. Electron 2006, 7, 155.

17. Park, J. W.; Kang, P.; Park, H.; Oh, H. Y.; Yang, J. H.; Kim, Y. H.; Kwon, S. K. Dyes Pigments 2010, 85, 93. 